\title{
Study on Problems in Beijing-Tianjin-Hebei Coordinated Industrial Development and Measures
}

\author{
Shuang Liu \\ School of Economics and Management, Beijing Jiaotong University, Beijing, China \\ 16120558@bjtu.edu.cn
}

Keywords: Beijing-Tianjin-Hebei, Industry synergy, Industrial structure.

\begin{abstract}
It is the 3rd anniversary of the Beijing-Tianjin-Hebei intergation as a national strategy, Beijing-Tianjin-Hebei integration becomes an important key issue again on the two sessions, the government work report also mentions they need to implement thoroughly this strategy. In the process of completing strategy, industrial cooperation is key part of Beijing-Tianjin-Hebei collaborative development. The strategy breaks the restriction of the administrative region, and makes three places become an economic organism and make achievement. For example, Hebei province introduced 4100 projects and collectd 3825 billion from Beijing and Tianjin in 2016, accounting for the province's total of $42 \%$ and $51 \%$, but there exists some problems. Therefore, this paper focuses on the trouble of industrial cooperation, and proposes corresponding measures to promote industrial development.
\end{abstract}

\section{京津冀产业协同发展存在的问题及对策}

\author{
刘爽 \\ 北京交通大学经济管理学院，北京，中国 \\ 16120558@bjtu.edu.cn
}

关键词：京津冀；产业协同发展；产业结构

中文摘要. 今年是京津冀协同发展上升为国家战略的三周年, 京津冀一体化再次成为两会的 重点议题，政府工作报告中提到要深入实施京津冀协同发展，为落实这一战略部署，产业协 同发展无疑是关键性突破，自产业协同发展战略实施以来，打破了行政区域的限制，三地成 为经济有机体，取得了一定的发展成就,2016年河北省从京津引进项目 4100 个、资金3825亿元， 分别占全省的 $42 \%$ 和 $51 \%$, 但是在产业协同发展过程中存在问题, 制约了京津冀一体化进程, 因此本文着重阐述了产业协同发展的困境，并且提出相应的措施以促进其产业协同发展。

\section{1. 引言}

20 世纪 80 年代以广州为代表的珠三角地区, 90 年代以上海浦东为代表的长三角地区, 以及 21 世纪以北京为代表的京津冀地区, 已经成为促进中国经济发展的三大增长极, 经过数 十年发展, 长三角和珠三角已经突出区域产业集群发展的强大经济效应。2016年, 珠三角地 区GDP占全国12.4\%, 长三角地高达 $19.8 \%$, 而京津冀地区仅占 $10 \%$, 且三地经济发展差异较大。 根据学术机构公布的《中国连片特困区发展报告》, “环京津贫困带” 中 33 个贫困县中河北 省占有 22 个, 在经济发达的京津之间, 存在如此贫困区域。因此实现京津冀区域一体化成为 当务之急, 产业协同无疑是最重要的条件。区域内产业间能否协同发展、产业结构能否合理 互补不仅关系到区域经济的发展质量, 更加与该区域能否发挥经济增长引领力量紧密联系。 


\section{2. 文献综述}

\section{1 理论基础}

产业协同发展理论可以追溯至哈肯的协同理论。20世纪70年代, 著名物理学家哈肯首次 提出 “协同” 的概念并创立了协同学, 着重探讨各种系统和现象中从无序到有序转变的共同 规律, 认为任何一个系统内的子系统之间的相互作用决定了该系统的整体行为, 如果子系统 内要素呈现无序凌状态, 说明子系统之间联系不够密切, 反之说明各子系统之间发挥了协同 效应。区域产业协同发展的目标是为实现整体地区的共同利益, 京津冀地区要相互作用、促 进区域协调机制的建立和运行，形成经济的协调有序发展状态，提高区域的综合实力。

产业协同发展的原理是根据地区间的优势和劣势进行资源分派, 可以用古典国际贸易理 论解释。（1）绝对优势理论, 由古典经济学家亚当・斯密提出, 他认为如果某国家的生产成 本低于其他国家, 该国就具有 “绝对优势” ，每个国家就会生产本国具有绝对优势的产品并 从其他国家交换不具有绝对优势的产品, 国际贸易得以形成。（2）大卫・李嘉图发展相对优 势理论, 如果某国生产一种产品的相对成本低于别国生产的相对成本, 该国在生产该种产品 拥有 “相对优势” , 各国通过出口相对成本较低的产品进口相对成本较高的产品, 实现贸易 互利。（3）要素禀赋论。赫克歇尔和俄林认为生产要素的禀赋和要素使用比例不同造成生产 的相对差异, 形成了相对优势, 国际贸易得以产生。三种理论本质上强调不同地区间应该根 据各自的优势进行区域分工合作，发展各自优势产业，提高要素的使用效率，提高经济效益。

在京津翼产业协同发展存在的问题中，马晓河（2014） ${ }^{[1]}$ 认为京津冀之间发展差距大、 产业结构既相似又相互之间竞争、缺少和谐机制的难题。孙虎（2015） ${ }^{[2]}$ 基于京津冀区域的 实际情况, 认为京津冀存在区域价值取向单一、市场活力不足、缺少承接能力的问题。魏丽 华 (2016) ${ }^{[3]}$ 通过实证分析认为区域产业结构同构度高, 经济发展差异悬殊是制约其产业发 展的主要障碍。在解决方法上, 张贵 (2014) ${ }^{[4]}$ 建议应当在国家层面设立京津冀协同发展引 导基金, 解决市场自主调节和行政指令无法解决的问题, 朱晓青 (2015) ${ }^{[5]}$ 认为要明确产业 定位、建立利益合作机制等促进京津冀产业协同发展。

\section{3. 京津冀产业协同面临的主要问题}

\section{1 三地产业结构差异明显}

本文选取2006年至2016年之间的数据, 统计京津冀三次产业增加值所占整个总产值的比 重以及计算2016年的区位商,判断其产业结构和产业之间是否存在合理的产业梯度。

表1 1996-2006年京津冀地区三次产业比重

\begin{tabular}{|c|c|c|c|c|c|c|c|c|c|}
\hline 地区 & \multicolumn{3}{|c|}{ 北京 } & \multicolumn{3}{|c|}{ 天津 } & \multicolumn{3}{|c|}{ 河北 } \\
\hline${ }^{{ }^{2}}$ 年份 & $\begin{array}{l}\text { 第一 } \\
\text { 产业 }\end{array}$ & $\begin{array}{l}\text { 第二 } \\
\text { 产业 }\end{array}$ & $\begin{array}{l}\text { 第三 } \\
\text { 产业 }\end{array}$ & $\begin{array}{l}\text { 第一 } \\
\text { 产业 }\end{array}$ & $\begin{array}{l}\text { 第二 } \\
\text { 产业 }\end{array}$ & $\begin{array}{l}\text { 第三 } \\
\text { 产业 }\end{array}$ & $\begin{array}{l}\text { 第一 } \\
\text { 产业 }\end{array}$ & $\begin{array}{l}\text { 第二 } \\
\text { 产业 }\end{array}$ & $\begin{array}{l}\text { 第三 } \\
\text { 产业 }\end{array}$ \\
\hline 2006 & 1.1 & 27 & 71.9 & 2.3 & 55.1 & 42.6 & 12.8 & 53.2 & 34 \\
\hline 2007 & 1 & 25.5 & 73.5 & 2.1 & 55.1 & 42.8 & 13.3 & 52.9 & 33.8 \\
\hline 2008 & 1 & 23.6 & 75.4 & 1.8 & 55.2 & 43 & 12.7 & 54.3 & 33 \\
\hline 2009 & 1 & 23.5 & 75.5 & 1.7 & 53 & 45.3 & 12.8 & 52 & 35.2 \\
\hline 2010 & 0.9 & 24 & 75. 1 & 1.6 & 52.4 & 46 & 12.6 & 52.5 & 34.9 \\
\hline 2011 & 0.8 & 23.1 & 76.1 & 1.4 & 52.4 & 46.2 & 11.9 & 53.5 & 34.6 \\
\hline 2012 & 0.8 & 22.7 & 76.5 & 1.3 & 51.7 & 47 & 12 & 52.7 & 35.3 \\
\hline 2013 & 0.8 & 22.3 & 76.9 & 1.3 & 50.6 & 48.1 & 12.4 & 52.1 & 35.5 \\
\hline 2014 & 0.7 & 21.4 & 77. 9 & 1.3 & 49. 4 & 49.3 & 11.7 & 51.1 & 37.2 \\
\hline 2015 & 0.6 & 19.6 & 79.8 & 1.3 & 46.7 & 52 & 11.5 & 48.3 & 40.2 \\
\hline 2016 & 0.5 & 19. 2 & 80.3 & 1. 2 & 44. 8 & 54 & 11 & 47.3 & 41.7 \\
\hline
\end{tabular}


根据上述表所示，北京市作为国家的经济政治中心，产业结构呈现 “三二一”顺序，按 照库兹涅茨法判定, 北京处在后工业化时代, 已成为以服务业为主的现代城市。考察三次产 业内部构成的变化, 发现第一产业逐年降低, 仅占地区生产总值中的微小份额, 第二产业份 额也在逐年下降, 第三产业产额逐年增加, 2016年已经到 $80.3 \%$, 以现代服务业和高新技术产 业为主, 处于产业链的顶端, 排名前四名的产业为金融业, 工业, 信息技术业, 批发和零售 业。天津作为该区域的另一核心城市, 产业结构同样是 “三二一” 结构, 第一产业占微小比 重，二三产业从2014年以前的的第二产业比重大于第三产业到2014年的基本持平到现在的第 三产业比重略高于第二产业, 处在产业链的中端, 在未来第三产业可以成为拉动天津经济迅 速发展的动力, 排名前四名的产业为工业, 批发和零售业, 金融业, 建筑业, 交通运输和仓 储邮政业。而河北省的产业结构这些年中产业结构依然是 “二三一” 模式, 第一产业比重较 于京津地区较大, 第二产业比较发达, 第三产业发展相对落后, 但情况在逐渐改善, 仍然处 于工业化初期。在服务业上处于产业链的低端, 排名前四名的产业为工业, 农林牧渔业, 批 发和零售业, 交通运输和仓储邮政业, 建筑业。

区位商是指特定区域某次产业产值占该区域总产值的比重与区域整体内该次产业产值占 总产值比重的比值，用以表示某一些产业在区域内的集中程度，计算公式如下：

$$
\boldsymbol{L}=\frac{V_{i j} / \sum_{i} V_{i j}}{\sum_{j} V_{i j} / \sum_{i j} V_{i j}}
$$

其中 L 代表某行业区位商的值，V 代表行业产值，i取值 1,2,3 分别代表各次产业，j 代表京津冀三省市。当区位商 $\mathrm{L}$ 大于 1 时表明产业集中度高于区域平均水平, 具备产业优 势, 数值越大优势越强; 反之亦然。如表所示:

表2２016年京津冀地区三次产业区位商

\begin{tabular}{|c|c|c|c|}
\hline $\begin{array}{c}\text { 地区 } \\
\text { 产业 }\end{array}$ & 第一产业 & 第二产业 & 第三产业 \\
\hline 北京 & 0.109847047 & 0.510418272 & 1.421497524 \\
\hline 天津 & 0.238001935 & 1.216149658 & 0.926289114 \\
\hline 河北 & 2.105401731 & 1.257816456 & 0.716092738 \\
\hline
\end{tabular}

根据2016年区位商数据显示, 京津冀三省市产业间梯度和产业技术层次落差明显, 各自 的优势产业互不相同, 客观上存在产业转移的必要性和可能性。北京第三产业以 1.42 的的区 位商彰显其第三产业的发达, 天津第二产业比较突出, 第三产业紧随其后, 京津两地第一产 业区位值低于 0.3 , 相反河北的第一产业在所有区位商中最大, 显示出第一产业对其经济增长 的重要性, 0.8 以下的区位商反映出河北省第三产业在京津冀地区的弱势地位。

\section{2 产业同构现象严重}

测度产业的相似程度可以采用联合国工业发展組织（UNIDO）提出的产业结构相似系数, 计算公式为:

$$
S_{A B}=\frac{\sum_{n} X_{A n} X_{B n}}{\sqrt{\left(\sum_{n} X^{2} A n \sum_{n} X^{2}{ }_{B n}\right)}}
$$

其中, $X_{A N} 、 X_{B N}$ 分别表示 $n$ 产业在A地区和B地区的产值占产业的比重, $S_{A B}$ 表示两地的产 业结构相似系数, 取值在 0 到 1 之间, 值越大则表明两地产业结构越相似, 区域分工程度越低, 反 
之则两地产业结构趋异, 分工程度较高, 根据京津冀地区1995-2016年间统计年鉴所提供的相 关数据，对京津冀地区三次产业的结构相似系数进行了估算，如表所示：

表3１995-2016年京津冀地区三次产业结构相似系数

\begin{tabular}{|c|c|c|c|c|c|c|c|}
\hline 年份 & 京津 & 京冀 & 津冀 & 年份 & 京津 & 京冀 & 津冀 \\
\hline 1995 & 0.959 & 0.961 & 0.915 & 2006 & 0.851 & 0.787 & 0.982 \\
\hline 1996 & 0.949 & 0.897 & 0.968 & 2007 & 0.838 & 0.77 & 0.98 \\
\hline 1997 & 0.94 & 0.881 & 0.969 & 2008 & 0.822 & 0.738 & 0.979 \\
\hline 1998 & 0.944 & 0.867 & 0.967 & 2009 & 0.846 & 0.768 & 0.978 \\
\hline 1999 & 0.937 & 0.864 & 0.968 & 2010 & 0.857 & 0.768 & 0.976 \\
\hline 2000 & 0.929 & 0.852 & 0.972 & 2011 & 0.851 & 0.752 & 0.976 \\
\hline 2001 & 0.922 & 0.842 & 0.97 & 2012 & 0.855 & 0.758 & 0.975 \\
\hline 2002 & 0.912 & 0.837 & 0.973 & 2013 & 0.864 & 0.758 & 0.973 \\
\hline 2003 & 0.899 & 0.836 & 0.977 & 2014 & 0.869 & 0.77 & 0.975 \\
\hline 2004 & 0.886 & 0.825 & 0.976 & 2015 & 0.882 & 0.793 & 0.977 \\
\hline 2005 & 0.871 & 0.803 & 0.98 & 2016 & 0.897 & 0.806 & 0.976 \\
\hline
\end{tabular}

在1995-2016年间, 京津与京冀产业结构相似系数出现了明显的下降, 分别从从 0.959 下 降到0.879, 0.915下降到0.806。可以发现, 随着京津冀一体化的推进, 这两个区域产业同构 现象有所改善, 北京的产业成功向天津和河北两地转移, 自从2011年这两个区域之间结构系 数呈现轻微上升期, 特别是京津地区, 这也说明天津正朝着服务业城市发展。而津冀两地之 间的三次产业结构相似系数却变化不大, 始终在围绕化 0.96 到 0.98 之间小幅波动。虽然部分 区域产业同构现象稍微缓解，但是总体上三区域产业结构相似程度较高，区域分工程度低。

\section{3 构建协同发展的经济社会环境差距过大}

相对均衡的地区经济发展是构成地区之间产业协同发展的基础，才会各自立足在自己优 势的情况下, 有效统筹产业分工、产业转移, 实现区域共赢局面, 但是三省市经济发展差距 过于悬殊, 以2016年为例,具体指标见下表:

表4 2016年京津冀三地经济发展主要指标

\begin{tabular}{|c|c|c|c|}
\hline 指标 & 北京 & 天津 & 河北 \\
\hline GDP（亿元） & 24899.3 & 17855.39 & 31827.9 \\
\hline 人均GDP（万元） & 11.5 & 11.43 & 4.26 \\
\hline 城镇居民可支配收入（元） & 57275 & 34074 & 29249 \\
\hline 农村居民可支配收入（元） & 23310 & 20076 & 11919 \\
\hline
\end{tabular}

根据指标在京津冀地区的对比, 我们可以发现, 尽管在GDP总量上, 河北占据绝对的优 势, 但是在各项均值则出现与京津两市相比的明显落差。人均GDP不足两市的一半, 城镇和 农村可支配人均收入也远落后于两市。根据上述产业结构的分析, 北京的第三产业占比达到 $80 \%$ ，天津则是服务业比重达到 $50 \%$, 而河北则仍有 $50 \%$ 以上的第二产业, 北京和天津作为 区域内两大中心城市, 依靠其政治、经济等优势, 发展速度较快, 处在产业链的中高端, 而 与之相邻的河北省发展相对滞后, 三大区域无法形成有利于区域经济发展的完整产业链, 不 仅不利于京津产业向周边地区的延伸与辐射, 也决定了河北对京津产业的支撑与承接的不足。

\section{4 产业协同发展的利益协调机制落后}

津冀三地产业协同发展遇到的困境之一是基于平等关系的利益协调机制落后，三地之间 在产业结构、经济发展等方面存在着较大差异, 优质资源和要素的单向流动方向性明显, 而 且三地尽管联系密切, 但均是独立的行政区域, 出于对地方和当前利益的考虑, 更多的从自 
身发展思考问题难以以区域和全局角度出发, 无法形成有效的区域之间利益协调机制。例如, 大多数央企的总部均在北京, 根据财税规定, 所有子公司都要将所得税交到北京总部所在地, 而只有增值税和城市维护建设税, 子公司可在其所在地缴纳, 所以这就可能会引起央企总部 不会从北京移出, 而河北不愿意接受对自己贡献小却又占据资源的企业。因此三地的产业和 生产总值取舍仍任重道远, 产业关系到三地的税收、就业等行政指标, 迫切需要建立市场化 的产业协同利益分配机制需要相关的补偿机制、社会保障制度的改革配套。

\section{4. 促进京津冀产业协同发展的建议}

\section{1 加强产业转移协作, 促进产业结构的优化升级}

加快京津冀地区产业转移协作, 坚持政府引导, 市场调控, 企业为核心的原则, 充分调 动三方的积极性，发展比较优势，产业错位发展，形成” $1+1+1>3$ ” 的共赢局面。三地政府 要促进多层次和全方位的产业转移对接平台的建设, 北京要加快产业转移的步伐, 转移不符 合北京定位的产业, 天津一方面承接北京的产业, 一方面和北京类似将不符合城市功能的产 业迁出, 河北要抓住契机, 瞄准京津产业转移重点区域精准招商, 立足引进能够带动行业发 展、优化生产力布局的优良项目, 政府要跳出官本位思维, 突破政策和行政壁垒, 打造优质 产业转移基地, 吸引京津产业转移, 有效拓展产业链, 产生规模效应, 形成与京津优势互补, 分工专业与协作一体化的特色产业集群。在对接层面上, 要注重企业、项目、园区等层面上 联动, 注重交通体系、生态环境等产业对接配套环境的完善, 保障产业对接的顺利实现。

\section{2 整体范围内对区域进行产业规划}

经前面论述, 京津冀均有各自的优势产业, 应重新分配各地产业优势, 重构区域内的产业 分工, 形成协调互补的产业分工体系, 构建主次分明, 合作有序的产业链。北京应重点发展 以高新技术业为代表的第三产业, 天津市一方面可以借助北京的优势发展科学技术, 促进第 三产业的进步, 另外要延续制造业和交通运输行业的优势; 就京冀之间的产业协同发展而言, 重点是优势产业间的错位发展和相互扶助, 河北省第一产业发达的特点要承接, 在原有产业 的基础上引进绿色生产技术, 开发新型产业项目, 有选择的接受来自北京的转移产业, 与天津 一样，利用转移产业逐渐发展第三产业; 对于津冀两地，产业协同应当集中在一二产业间， 天津要利用河北的优势满足对第一产业产品的需求, 河北则借助天津的物流运输业的健全方 便国际贸易, 两地第二产业存在严重的同构现象, 因此两地需要进行以区域合作为导向的产 业间的分工协作，围绕第二产业价值链做好产业内部协同分工和上下游合作。

\section{3 解决发展落差, 拉动河北经济发展}

2016年《“十三五” 时期京津冀国民经济和社会发展规划》正式公布，规划将解决河北 与京津的发展落差上升达国家层面来部署, 在这样的背景下, 政府和有关部门更要积极落实 政策, 制定因地制宜的发展规划, 大力发展河北的经济, 特别是提高人均GDP, 一方面要利用 得天独厚的自然和地理资源发展优势产业, 调整区域布局, 区别于京津两地的优势产业, 选 择互补的行业, 扩大优势范围, 提高机械制造化水平, 提高产业整体素质和竞争力, 培养属 于自己的增长极。另外一方面要借产业转移推动传统产业转型升级, 加快化解产能过剩、淘 汰落后产能的步伐, 遏制产能过剩行业继续扩张, 加强增量产能准入管理, 促进存量产能调 整优化。 ${ }^{[8]}$

\section{4 完善区域京津冀地区产业协同发展的利益协调机制}

首先各方要遵循平等互利的利益协调原则, 在区域内搭建三方协商平台, 参与主体表达 利益诉求, 尤其是处于相对弱势的河北要优先表达他们的观点想法。其次, 各方要通过调整 各地的产业政策, 利用不同区域的发展优势, 合理实现产业链条分布, 坚持以市场调配资源 
为主, 政府发挥经济职能为引导, 不同产业利益在不同地区实现合理分享, 对遭受损失的一 方给予资金补助或补偿, 形成促使京津冀区域整体受益、合理分配资源的利益协调机制。最 后, 加强监督产业利益协调机制的落实情况, 必要时可建立法律法规和地区规章制度统筹协 调整体与局部的关系，提高区域内整体实力，保持京津冀地区利益协调机制的长期有效性。

\section{5. 结论}

综上所述，目前京津冀地区在产业协同发展过程中面临着产业结构差异明显且同构现象 严重等主要挑战。京津冀产业协同发展是一个非常复杂的系统工程, 如何促进产业的协同发 展, 实现三地产业资源的合理配置, 实现区域产业结构定位科学、产业规划布局合理, 产业 优势互补的任务任重而道远, 这需要加强产业分工协作, 促进产业结构优化升级; 各地准确 定位, 认清各自的产业优势与劣势, 合理规划产业协调; 解决河北经济发展的短板, 完善促 进产业协同发展的利益分配机制, 保证协同发展工作公平高效的发展。努力完成优化提升首 都核心功能、完善城市形态、打造现代化新型首都圈, 真正成为促进中国经济发展的增长极。

\section{References}

[1] M. Xiaohe, Promoting the integration of Beijing, Tianjin and Hebei based on national strategic level, Journal of Chinese Academy of Governance, vol. 04, pp. 28-32, 2014.

[2] S. Hu, Study on problems in Beijing, Tianjin and Hebei coordinated industrial development and recommendations, China Soft Science, vol. 07, pp. 68-72, 2015.

[3] W. Lihua, Study on problems in Beijing, Tianjin and Hebei coordinated industrial development, Research on Developmen, vol. 02, pp. 117-121, 2016.

[4] Z. Gui, W. Shuqiang and L.Shal, Study on coordination between Beijing-Tianjin-Hebei based on industry matching and transfer, Economy and Management, vol. 04, pp. 14-20, 2014.

[5] Z. Xiaoqing, Study on the coordinated development of Beijing, Tianjin and Hebei industries, Expanding Horizons, vol. 01, pp. 104-109, 2015.

[6] W. Hongqiang, Reconstruction of industrial chain: New Thoughts on the coordinated development of Beijing, Tianjin and Hebei industries, Chinese Cadres Tribune, vol. 02, pp. 72-74, 2016.

[7] J. Ya, Research on the industrial coordination development in Beijing-Tianjin-Hebei area, Capital University of Economics and Business, 2016.

[8] A. Yan, H .Xiaoya, G. Xiao, The countermeasures of Hebei based on the enterprise view in Beijing-Tianjin-Hebei industry coordinated development, Reformation \& Strategy, vol. 03, pp. 114-117, 2017. 